\title{
Relationship between childhood sexual abuse and attitudes toward premarital sexual permissiveness among middle school students in Luzhou, China
}

\author{
Zhang Rong ${ }^{1}$, Zhang Wen², Liao Maoxu' ${ }^{1}$ Liu Ya ${ }^{1}$, Fan Song ${ }^{1}$, Wei Hui ${ }^{1}$, Tan Xiaozhen ${ }^{1}$ and Ye Yunli ${ }^{*}$
}

\begin{abstract}
Background: In recent years, the number of adolescents engaging in premarital sex has increased, and an increasing number of childhood sexual abuse (CSA) cases have been reported in China. Many studies have indicated that CSA has a well-established association with risky sexual activities. However, only a limited number of studies have explored possible reasons for this association among middle school students, a population that may engage in premarital sex, which is critical for the development of interventions to prevent risky sexual behavior. Based on random samples of middle school students from a Chinese city, this article investigated the relationship between CSA and students' premarital sexual permissiveness (PSP).
\end{abstract}

Methods: In a cross-sectional study conducted between 2016 and 2017 in Luzhou, China, 2292 middle school and high school students aged 12-18years were recruited by multistage random sampling. All students were administered anonymous questionnaires. Multiple linear regression and binary logistic regression analyses were conducted to analyze the relationship between CSA and PSP.

Results: The prevalence of CSA was 15.4\% (354/2292; 95\% Cl: 14-16.9\%). A higher percentage of male respondents (18.2\%) than female respondents (12.9\%) had experienced CSA. A positive association between CSA and PSP was found among students. Respondents who had suffered CSA exhibited greater PSP, and this relationship was observed in the male sample, female sample and the total student sample in Luzhou $(\beta=-3.76, P<0.05 ; \beta=-2.79, P<0.05$; and $\beta=-2.84, P<0.05$, respectively). Respondents who had suffered CSA were also more likely to express a double standard about premarital sex (odds ratio $[O R]=1.41, P<0.05$ ), especially among male students (odds ratio [OR] $=1.63, P<0.05)$.

Conclusions: Sex differences in CSA and the relationship between CSA and PSP were significant among this large sample of middle school students in Luzhou (China). The findings suggest that experiencing CSA may be closely related to youth attitudes toward premarital sex, especially among males. Therefore, it is important to emphasize the prevention of CSA and provide adolescent reproductive health programs to reduce the impact of CSA on sexual cognition and attitude, prevent premarital sex and promote positive attitudes toward sexual equality for middle school students.

Keywords: Child sexual abuse, Premarital sexual permissiveness, Middle school students, China

*Correspondence: wushuangyewu@163.com

${ }^{1}$ School of Public Health, Southwest Medical University, Luzhou, China

Full list of author information is available at the end of the article

(C) The Author(s) 2022. Open Access This article is licensed under a Creative Commons Attribution 4.0 International License, which permits use, sharing, adaptation, distribution and reproduction in any medium or format, as long as you give appropriate credit to the original author(s) and the source, provide a link to the Creative Commons licence, and indicate if changes were made. The images or other third party material in this article are included in the article's Creative Commons licence, unless indicated otherwise in a credit line to the material. If material is not included in the article's Creative Commons licence and your intended use is not permitted by statutory regulation or exceeds the permitted use, you will need to obtain permission directly from the copyright holder. To view a copy of this licence, visit http://creativecommons.org/licenses/by/4.0/. The Creative Commons Public Domain Dedication waiver (http://creativeco mmons.org/publicdomain/zero/1.0/) applies to the data made available in this article, unless otherwise stated in a credit line to the data. 


\section{Background}

In the last three decades, young people's attitudes toward premarital sex in China have changed substantially, shifting from conservative to open. This phenomenon is highly related to the increased influence of Western culture after economic reform and opening up, the implementation of policies on late marriage and late childbearing in China, and early puberty in the general population. The prevalence of premarital sex has also risen dramatically $[1,2]$. The health risks of teenagers' premarital sex behaviors, such as HIV infection and other sexually transmitted infections (STIs) [3], unplanned pregnancy [4], and the risks associated with having multiple sexual partners [5], could lead to negative physical and psychological consequences and pose a serious threat to the healthy development of adolescents. Data on the prevalence of premarital sex among male adolescents in two other Asian cities are not optimistic [6], showing prevalences of $24.1 \%$ in Taipei, Taiwan, and $5.2 \%$ in Hanoi, Vietnam.

Youth have been identified as the population group that is the most vulnerable to unwanted pregnancy, HIV infections and STIs. A study on 4769 female undergraduates reported that $18 \%$ of the students had previously had sex and that the proportions of students with self-reported pregnancies and STIs were 17.5 and 20.4\%, respectively [7]. A cross-sectional study including university students from 49 universities across 7 cities in China indicated that approximately one-third of unmarried female university students engaging in sexual intercourse had experienced unintended pregnancy [8]. Seventyseven percent of newly diagnosed HIV/AIDS patients in China were students from colleges and universities, and the main transmission route was sexual contact [9].

The prevalence of childhood sexual abuse (CSA) is 6-18.7\% in teenagers aged 18 and below in China [1012]. However, CSA data may have been underreported in past studies, as an increasing number of CSA cases have been recently reported in Chinese media and professional journals. Chinese population studies have also found that CSA is related to early sexual debut among children and adolescents in rural areas [13-15]. Among the number of determinants of premarital sex [16-19], one important factor is CSA [20]. However, there is sparse existing evidence indicating whether CSA affects attitudes toward premarital sex in middle school students and whether CSA potentially affects the premarital sex behavior of university students and school dropouts.

Researchers have found that sexual attitudes are significantly positively correlated with sexual behaviors [21]. Research has shown that most students are young (1618 years) at their first exposure to premarital sex [22], which indicates that the sexual attitudes of this age group could provide more insights into the correlations of sexual behaviors. Recent research on premarital sex has mainly focused on the determinants and health effects of sexual behaviors [3], and most of them recruited college students [23] or adults [19, 24, 25] as the subjects. Middle school students, as a population with a potential high risk of engaging in premarital sex, have rarely been included in existing studies. In addition, social cognitive theory (SCT) is widely used as a theoretical structure to explain individual behaviors as a result of three factors: environment, person, and behavior [26]. The model believes that every two out of the three factors can interact with each other and then influence the third factor; for example, human behaviors can be developed and modified by the direct experience of individuals and the structures of the environment $[27,28]$. Therefore, we suspect that CSA as a direct personal experience may affect premarital sex. In addition, according to knowledge, attitude, belief, practice (KAP) theory, behavior and attitude are closely related. Therefore, it is suitable to use SCT to discuss the influence of CSA on the attitude of middle school students toward premarital sex.

Therefore, it is vital to understand the factors associated with attitudes toward premarital sexual behavior in adolescents. Additionally, the question of how CSA influences adolescents' attitudes and beliefs about premarital sexual initiation in a society dominated by Confucian cultural norms has rarely been studied. The present study could support further efforts for the intervention and prevention of high-risk sexual behavior based on the following four major research objectives: (a) to understand attitudes toward premarital sex among middle school students; (b) to understand the prevalence of CSA among middle school students; (c) to explore the determinants of middle school students' attitudes toward premarital sexual behavior; and (d) to determine whether CSA has an association with attitudes toward premarital sexual behavior and the strength of the association.

\section{Methods \\ Study design and sample}

The research data were extracted from a school-based comprehensive sex education program in Luzhou, Sichuan Province. Luzhou City is a third-tier city in China located in the south-central part of Sichuan Province. Its economic development level is representative of the vast majority of cities in central China. The data for this article were collected via a cross-sectional survey of 2396 students aged 12-18years from eight different middle schools in urban and rural areas of Luzhou that was conducted by a team of researchers from Southwest Medical University. In this study, 2292 students were included in the analysis. 
Multistage random sampling was used in the study. The seven administrative divisions of Luzhou City can be divided into three categories according to their economic status. Among the seven divisions, two (Jiangyang and Longmatan) have a good economy, three (Naxi, Luxian and Hejiang) have a fair economy, and two (Gulin and Xuyong) have a poor economy. With reference to the yearbook of middle school students' statistics, the proportion of middle school students across the three different economic categories is 1:2:1. Therefore, in the first stage, the numbers of selected administrative divisions from individual economic categories are 1, 2 and 1. We randomly selected four administrative divisions (Longmatan, Luxian, Hejiang, and Gulin) from the seven divisions in Luzhou. In the second stage, two schools in each division, including one school in an urban area and one school in a rural area, were randomly selected. The number of students per class in public secondary schools is relatively constant (approximately 45 students) in Luzhou. In the third stage, two classes in each grade were selected. Thus, eight schools with an average of 300 individuals in each were selected. The "Sichuan Adolescent Sexual Health Questionnaire", which has been published elsewhere [29], was adapted by the research teams for the survey. The survey was conducted by investigators with unified training from late Dec 2016 to early Jan 2017. Respondents independently completed the anonymous questionnaire with the guidance provided. This study received approval from the Medical Ethics Committee at Southwest Medical University and collaborating local organizations.

\section{Measures}

\section{Sociodemographic variables}

The sociodemographic variables in the analysis were separated into three sets. The first set of variables represented the characteristics of respondents, namely, sex and grade (middle school/high school). Sex was a self-reported dichotomous variable, as was grade. The second set of variables included rural/urban residence, self-reported economic status and one-child family. Economic status was self-reported according to three categories (low, middle, and high). The third set of variables concerned parents' information and included living or deceased parents and father's/mother's educational level. Educational level was based on the highest level of education parents had completed. Additional variables included history of exposure to pornographic content on electronic media, parents' or friends' approval of premarital sex and history of dating or falling in love with somebody.

\section{Gendered attitudes toward premarital sex}

Premarital sexual permissiveness (PSP) scores were calculated based on modified Guttman scales with six items [30]; PSP scores indicate an individual's approval of a sexual act (coitus) under different conditions (with a casual acquaintance, with a boyfriend/girlfriend, or with a fiancé and fiancée). One scale (the female scale) is composed of three items measuring the respondent's perceived level of agreement with females initiating intimate behaviors (coitus) at various stages before marriage (with a stranger or with someone whom the person is not in love with, with an unattached boyfriend whom the person is in love with, or with a fiancé whom the person is engaged to), and the other scale (the male scale) is composed of three similar items that ask about appropriate behavior for males. A Likert scale was utilized for scoring. For each item, the possible responses were 1 = "Strongly Agree," $2=$ "Agree," $3=$ "Neutral," $4=$ "Disagree," and 5= "Strongly Disagree." The scores ranged from 3 to 15 for each scale, with larger numbers indicating that respondents more strongly disapproved of intimate behaviors at the relevant stage. For convenience, we standardized the scores on a scale from 0 to 100 . That is, the highest score of 15 corresponds to 100 points on the percentile system, so if the actual score of the student on the scale is $\mathrm{x}$ points, then the percentile scale score is equal to $x^{*}(100 / 15)$. Respondents with higher scores were considered more intolerant. The standardized Cronbach's $\alpha$ coefficients for the two scales were 0.86 and 0.87 . In addition, if respondents showed higher permissiveness regarding males' premarital sexual behavior than that regarding females' premarital sexual behavior, he or she was identified as having a double standard.

\section{Adolescents' attitudes toward gender roles}

Studies have shown that gender role attitudes are also an important factor related to premarital sex [31]. The survey also collected data on respondents' attitudes toward gender roles. Eleven items were included, and they were scored on a Likert scale where $1=$ "Strongly Agree," $2=$ "Agree," $3=$ "Neutral," $4=$ "Disagree" and $5=$ "Strongly Disagree." The 11 items were as follows: (a) "Home affairs should be determined by the man in charge," (b) "The most important task for a mother is to take care of her family and children," (c) "The most important task for a father is to work hard to earn money," (d) "Compared with boys, girls should start doing housework as young as possible," (e) "Boys should receive a higher level of education than girls," (f) "Parents should share the responsibility of raising children and doing housework," (g) "Women can do what men do," (h) "Contraception is mostly women's responsibility," (i) "For women, the greatest happiness is 
to find a good husband," (j) "When jobs are scarce, men should be given priority over women," and (k) "A woman can take the lead to express that she likes a man." We reversed the scoring of items (f), (g) and (k) and summed the respondent's scores to calculate the index. To obtain a clear view of the results, we again standardized the scores on a scale from 0 to 100 . The Cronbach's $\alpha$ coefficient was 0.686 . Higher scores indicated more male chauvinism in the respondents' conceptions and greater adherence to traditional gender roles.

\section{Childhood sexual abuse}

Referring to previous literature [29], we defined CSA as the experience of any of the following behaviors before age 18: (a) being the target of unwanted verbal flirtation (verbal sexual harassment); (b) being touched or hit in one's chest or private parts; (c) being exposed to another naked person with the purpose of being made to feel inferior (forced exposure to pornography); (d) being forced to appear naked in front of someone else; (e) being forced to kiss another person, touch his or her body, take his or her clothes off and so on; and (f) being forced to engage in oral sex, anal sex, vaginal sex, genital friction or other sexual behaviors. Among them, items (a) (d) were considered sexual harassment, item (e) was considered obscene, and item (f) was considered sexual assault.

\section{Analysis}

We used EpiData Version 3.1 software (EpiData Association., DNK) and double entry to build the database. Subsequently, SPSS Statistics Version 22.0 (IBM, Inc., Amonk, NY) was used for data analysis. Percentages were used to describe the sociodemographic characteristics of the objects. Second, the P-P graph showed that the distribution of PSP had a normal trend, which suggests the use of a parametric approach for data analysis. We applied a $t$ test and analysis of variance to examine the differences in PSP scores of the respondents. The $\chi^{2}$ test was used to examine differences in respondents' experience of CSA. The assumptions guiding the use of multiple linear regression were critically examined, and we ensured that none of these assumptions were violated. The independence index D-W statistics were 1.859, 1.907, and 1.925. There were no problems with collinearity. Normality and homogeneity of variance were basically satisfied, as shown in the residual graph (Supplementary Fig. 1, Additional file 1). Multiple linear regression was used to examine the influence of the sociodemographic characteristics, CSA, and gender role attitudes of adolescents' PSP in case of data compliance with assumptions. Logistic regression was used to explore the influencing factors of gendered double standards.

\section{Results}

Description of the sociodemographic characteristics of the respondents

A total of 2396 students were surveyed, and 2292 responses were valid. The sociodemographic characteristics of the respondents are shown in Table 1. More than $50 \%$ of the students lived in rural areas. One-third of the respondents had previously dated or fallen in love with somebody. Nearly $70 \%$ of respondents reported that their parents and friends did not object to premarital sex, and $16 \%$ of the respondents had accessed pornographic content on electronic media (Table 1).

\section{Premarital sexual permissiveness}

The $t$ test and variance analysis show significant differences in PSP according to sex, grade, place of residence, self-reported economic status, onechild family status of the respondents, education level of the father and mother, a history of dating or falling in love with somebody, approval from friends and parents regarding premarital sex, a history of exposure to pornographic content on electronic media and experience of CSA. Both male and female respondents reported that males would have greater PSP than females. High school students expressed more permissiveness than middle school students. The following students were more permissive: students who resided in rural areas, had lower self-reported economic status, were members of one-child families, had previously dated or fallen in love with somebody, had friends and parents who approved of premarital sex, had previously been exposed to pornographic content on electronic media or had ever experienced CSA (Table 2).

\section{Respondents' experience of childhood sexual abuse}

The prevalence of CSA was 15.4\% (354/2292; 95\% CI: $14-16.9 \%)$. The prevalence in males was higher than that in females $(P<0.001)$. The prevalence of CSA was different across different self-reported economic statuses $(P<0.05)$. Based on multiple comparisons, both male and female respondents reported that students with low self-reported economic status had more PSP than students with a middle selfreported economic status. Youth with a history of exposure to pornographic content on electronic media or a history of dating or falling in love with somebody had experienced a higher prevalence of CSA than others $(P<0.001)$. Female students whose parents did not approve of premarital sex had a lower rate of CSA (Table 3). 
Table 1 Frequencies and percentages of sociodemographic characteristics of the respondents (n (\%))

\begin{tabular}{|c|c|}
\hline Sociodemographic characteristics & Frequency (Percent) \\
\hline \multicolumn{2}{|l|}{ Sex } \\
\hline Male & $1091(47.6)$ \\
\hline Female & $1201(52.4)$ \\
\hline \multicolumn{2}{|l|}{ Grade } \\
\hline Middle school & $1198(52.3)$ \\
\hline High school & $1094(47.7)$ \\
\hline \multicolumn{2}{|l|}{ Left-behind student $^{\mathrm{a}}$} \\
\hline Yes & $1258(57.2)$ \\
\hline No & $940(42.8)$ \\
\hline \multicolumn{2}{|l|}{ Residence $^{\mathrm{a}}$} \\
\hline Rural & $1274(56.1)$ \\
\hline Urban & $998(43.9)$ \\
\hline \multicolumn{2}{|l|}{ Self-reported economic status ${ }^{\mathrm{a}}$} \\
\hline Low & $627(27.9)$ \\
\hline Middle & $1555(69.1)$ \\
\hline High & $68(3.0)$ \\
\hline \multicolumn{2}{|l|}{ One-child family } \\
\hline Yes & $285(12.4)$ \\
\hline No & 2007 (87.6) \\
\hline \multicolumn{2}{|l|}{ Divorced parents } \\
\hline Yes & $216(9.4)$ \\
\hline No & $2076(90.6)$ \\
\hline \multicolumn{2}{|l|}{ Living or deceased parents } \\
\hline At least one parent deceased & $106(4.6)$ \\
\hline No parent deceased & $2186(95.4)$ \\
\hline \multicolumn{2}{|l|}{ Father's education level ${ }^{\mathrm{a}}$} \\
\hline Primary school or below & $715(34.5)$ \\
\hline Middle school & $1057(51.0)$ \\
\hline High school and above & $300(14.5)$ \\
\hline \multicolumn{2}{|l|}{ Mother's education level ${ }^{\mathrm{a}}$} \\
\hline Primary school or below & $1040(51.8)$ \\
\hline Middle school & $742(36.9)$ \\
\hline High school and above & $227(11.3)$ \\
\hline \multicolumn{2}{|c|}{ History of dating or falling in love with somebody ${ }^{a}$} \\
\hline Yes & $724(33.2)$ \\
\hline No & $1460(66.9)$ \\
\hline \multicolumn{2}{|l|}{ Friends' approval of premarital sex } \\
\hline Yes and other responses & $1785(77.9)$ \\
\hline No & $507(22.1)$ \\
\hline \multicolumn{2}{|l|}{ Parents'approval of premarital sex } \\
\hline Yes and other responses & $1672(73.0)$ \\
\hline No & $620(27.1)$ \\
\hline \multicolumn{2}{|c|}{ History of exposure to pornographic content on electronic media } \\
\hline Yes & $367(16.0)$ \\
\hline No & $1925(84.0)$ \\
\hline
\end{tabular}

${ }^{\mathrm{a}}$ Missing values
Relationship between childhood sexual abuse and premarital sexual permissiveness

In the multivariate analysis, we used male respondents' attitudes toward male premarital sex and female respondents' attitudes toward female premarital sexual behavior as indicators of male and female respondents' attitudes, respectively. Among all students, those who had experienced CSA were more permissive about premarital sex $(\beta=-2.84, P<0.05)$. This relationship was also found among both the male and female student samples $(\beta=-3.76$ and $P<0.05$ for the male student sample and $\beta=-2.79$ and $P<0.05$ for the female student sample). Students who were in high school, were members of a one-child family, were not left-behind students, had lower scores for gender role attitudes (less traditional gender norms), had previously been exposed to pornographic content on electronic media, had previously dated or fallen in love with somebody, and had friends and parents who approved of premarital sex showed greater permissiveness. In addition, girls reported less PSP than boys $(\beta=6.18, P<0.001)$ (Table 4$)$.

Those who had experienced CSA were more likely to express double standards about premarital sex (odds ratio $[O R]=1.41, P<0.05)$, especially among male students (odds ratio $[O R]=1.63, P<0.05$ ) (Table 5). Generally, male students who had lower gender role attitude scores (less traditional gender norms), had suffered CSA, or had previously been exposed to pornographic content on electronic media were more likely to express double standards. Female students who had previously dated or fallen in love with somebody or had lower gender role attitude scores (less traditional gender norms) were also more likely to express double standards about PSP (Table 5).

\section{Discussion}

Attitude determines behavior, as shown by KAP theory. The middle school period is a crucial period for the formation of adolescents' thoughts and values. Students' attitudes toward premarital sex in this period influence their sexual behavior patterns in college and even in adulthood. A positive association between CSA and PSP was found among middle school students in Luzhou. The findings of this study provide a new perspective and strategy for the intervention of adolescent premarital sex.

Our findings suggested obvious sex differences in permissive sexual attitudes. The results of the multiple linear regression models demonstrated that male middle school students reported more permissive sexual attitudes than female middle school students. This difference was consistent in the male, female and general samples, as we expected and in line with empirical findings stressing 
Table 2 Respondents' mean premarital sexual permissiveness scores, grouped by sociodemographic characteristics (Total=2292, Male $=1091$, Female $=1201$ )

\begin{tabular}{|c|c|c|c|c|c|c|c|c|c|}
\hline \multirow[t]{2}{*}{ Sociodemographic characteristics } & \multicolumn{3}{|c|}{ Male \& female scales } & \multicolumn{3}{|c|}{ Male scale } & \multicolumn{3}{|c|}{ Female scale } \\
\hline & Total & Male & Female & Total & Male & Female & Total & Male & Female \\
\hline \multicolumn{10}{|l|}{ Sex } \\
\hline Male & $80.29^{* * *}$ & - & - & $79.98^{* *}$ & - & - & $80.61^{* *}$ & - & - \\
\hline Female & 90.36 & - & - & 90.30 & - & - & 90.42 & - & - \\
\hline \multicolumn{10}{|l|}{ Grade } \\
\hline Middle school & $87.84^{* *}$ & $84.30^{* *}$ & $91.12^{*}$ & $87.55^{*}$ & $83.97^{* *}$ & 90.90 & $88.08^{* *}$ & $84.60^{* *}$ & $91.30^{*}$ \\
\hline High school & 83.18 & 75.84 & 89.57 & 83.10 & 75.54 & 89.69 & 83.33 & 76.17 & 89.50 \\
\hline \multicolumn{10}{|l|}{ Left-behind student } \\
\hline Yes & $86.59^{*}$ & 80.58 & $91.52^{* *}$ & $86.51^{*}$ & 80.38 & $91.56^{* *}$ & $86.75^{*}$ & 80.91 & $91.51^{* *}$ \\
\hline No & 84.41 & 80.21 & 88.71 & 84.14 & 79.87 & 88.56 & 84.58 & 80.46 & 88.80 \\
\hline \multicolumn{10}{|l|}{ Residence } \\
\hline Rural & $86.65^{* *}$ & 80.71 & $91.33^{* *}$ & $86.48^{* *}$ & 80.42 & $91.28^{*}$ & $86.85^{* *}$ & 81.07 & $91.35^{* *}$ \\
\hline Urban & 84.25 & 79.87 & 88.93 & 84.01 & 79.54 & 88.85 & 84.45 & 80.15 & 89.06 \\
\hline \multicolumn{10}{|l|}{ Self-reported economic status } \\
\hline Low & $85.11^{*}$ & 79.69 & 90.69 & $84.78^{*}$ & 79.05 & $90.69^{*}$ & $85.66^{*}$ & 80.62 & 90.78 \\
\hline Middle & 85.87 & 80.49 & 90.33 & 85.91 & 80.29 & 90.29 & 85.91 & 80.59 & 90.33 \\
\hline High & $80.98^{b}$ & 78.97 & 85.44 & $80.98^{\mathrm{a}}$ & 79.36 & $84.56^{\mathrm{a}}$ & $81.07^{\mathrm{a}, \mathrm{b}}$ & 78.57 & 86.33 \\
\hline \multicolumn{10}{|l|}{ One-child family } \\
\hline Yes & $80.71^{* *}$ & $76.03^{*}$ & $86.37^{* *}$ & $79.93^{* *}$ & $75.25^{* *}$ & $85.65^{* *}$ & $81.57^{* *}$ & $77.00^{*}$ & $87.09^{* *}$ \\
\hline No & 86.30 & 81.01 & 90.84 & 86.18 & 80.79 & 90.86 & 86.39 & 81.22 & 90.82 \\
\hline \multicolumn{10}{|l|}{ Divorced parents } \\
\hline Yes & 84.06 & 78.44 & 88.76 & 83.74 & 78.06 & 88.45 & 84.56 & 78.99 & 89.19 \\
\hline No & 85.75 & 80.47 & 90.53 & 85.57 & 80.17 & 90.50 & 85.91 & 80.77 & 90.55 \\
\hline \multicolumn{10}{|l|}{ Living or deceased parents } \\
\hline At least one parent deceased & 86.50 & 82.89 & 89.45 & 86.27 & 82.81 & 89.01 & 86.87 & 82.96 & 90.06 \\
\hline No & 85.55 & 80.17 & 90.40 & 85.36 & 79.85 & 90.37 & 85.73 & 80.50 & 90.44 \\
\hline \multicolumn{10}{|l|}{ Father's education level } \\
\hline Primary school or below & $86.28^{* *}$ & 79.89 & $90.94^{*}$ & $86.11^{* *}$ & 79.27 & $91.14^{*}$ & $86.52^{* *}$ & 80.51 & $90.83^{*}$ \\
\hline Middle school & 85.72 & 79.80 & 90.80 & 85.48 & 79.58 & 90.58 & 85.90 & 80.10 & 90.91 \\
\hline High school and above & $82.00^{\mathrm{ab}}$ & 79.08 & $86.95^{\mathrm{ab}}$ & $82.20^{\mathrm{ab}}$ & 79.42 & $86.98^{\mathrm{ab}}$ & $81.75^{\mathrm{ab}}$ & 78.68 & $86.91^{\mathrm{ab}}$ \\
\hline \multicolumn{10}{|l|}{ Mother's education level } \\
\hline Primary school or below & $86.48^{* * *}$ & 80.20 & $91.17^{* *}$ & $86.27^{*}$ & 79.63 & $91.28^{* *}$ & $86.64^{* *}$ & 80.69 & $91.07^{*}$ \\
\hline Middle school & $84.51^{\mathrm{a}}$ & 78.74 & 90.23 & $84.37^{\mathrm{a}}$ & 78.71 & 90.06 & $84.70^{\mathrm{a}}$ & 78.95 & 90.38 \\
\hline High school and above & $82.26^{\mathrm{a}}$ & 78.52 & $86.38^{\mathrm{ab}}$ & $82.03^{\mathrm{a}}$ & 78.29 & $86.16^{\mathrm{ab}}$ & $82.50^{\mathrm{a}}$ & 78.75 & $86.60^{\mathrm{ab}}$ \\
\hline \multicolumn{10}{|c|}{ History of dating or falling in love with somebody } \\
\hline Yes & $80.22^{* *}$ & $73.76^{* *}$ & $87.38^{* *}$ & $80.14^{* *}$ & $73.75^{* *}$ & $87.33^{* *}$ & $80.35^{* *}$ & $73.90^{* *}$ & $87.47^{* *}$ \\
\hline No & 88.43 & 84.28 & 91.85 & 88.25 & 83.97 & 91.79 & 88.59 & 84.58 & 91.89 \\
\hline \multicolumn{10}{|l|}{ Friends'approval of premarital sex } \\
\hline Yes and other responses & $83.74^{* *}$ & $79.21^{* *}$ & $88.71^{* *}$ & $83.46^{* *}$ & $78.88^{* *}$ & $88.91^{* *}$ & $84.02^{* *}$ & $79.55^{* *}$ & $88.53^{* *}$ \\
\hline No & 92.09 & 86.92 & 94.29 & 92.19 & 86.76 & 93.97 & 91.92 & 87.08 & 94.51 \\
\hline \multicolumn{10}{|l|}{ Parents' approval of premarital sex } \\
\hline Yes and other responses & $83.78^{* *}$ & $79.34^{* *}$ & $89.01^{* *}$ & $83.45^{* *}$ & $78.92^{* *}$ & $88.82^{* *}$ & $84.09^{* *}$ & $79.74^{*}$ & $89.22^{* *}$ \\
\hline No & 90.41 & 84.91 & 92.67 & 90.58 & 85.18 & 92.85 & 90.24 & 84.86 & 92.46 \\
\hline \multicolumn{10}{|c|}{ History of exposure to pornographic content on electronic media } \\
\hline Yes & $74.44^{* *}$ & $72.13^{* *}$ & $86.26^{*}$ & $74.47^{* *}$ & $72.02^{* *}$ & $86.90^{*}$ & $74.47^{* *}$ & $72.29^{* *}$ & $85.73^{*}$ \\
\hline No & 87.70 & 83.48 & 90.57 & 87.47 & 83.08 & 90.48 & 87.93 & 83.88 & 90.66 \\
\hline \multicolumn{10}{|l|}{ History of CSA } \\
\hline Yes & $80.34^{* * *}$ & $74.52^{* *}$ & $87.61^{*}$ & $80.16^{* *}$ & $74.01^{* *}$ & $87.87^{*}$ & $80.52^{* *}$ & $74.91^{* *}$ & $87.47^{*}$ \\
\hline No & 86.53 & 81.54 & 90.76 & 86.34 & 81.27 & 90.66 & 86.73 & 81.85 & 90.86 \\
\hline
\end{tabular}


that adolescents' sexuality develops, at least on certain dimensions, in a gender-specific way [13, 32]. Several explanations for this difference have been proposed. First, gendered attitudes toward PSP may be due to the different restrictions imposed on male and female sexual behaviors under Confucianist cultural norms. Confucianism, collectivism, male chauvinism, and asceticism are important features of China's culture, and these aspects have played an important role in shaping the beliefs and behaviors of much of the population [33]. For example, a young girl is not encouraged to take the initiative in expressing her affections to a man; instead, a young man is encouraged to take the initiative. Sexual activity is taboo and forbidden before marriage. Second, feelings of shame or guilt may cause female middle school students to underreport their actual attitudes [32]. Third, a lack of sex education at all ages creates a barrier for students' understanding of different forms of CSA, and males are exposed to pornography earlier and more easily than females [34, 35].

The prevalence of CSA among Luzhou middle school students was higher than that reported in prior metaanalyses [36] and another study, where the overall lifetime prevalence of CSA was $8 \%$ [37]. One possible explanation is that studies on CSA usually use retrospective self-reporting methods, which inherently involve some recall bias. Such bias increases as respondents age [38]. Since our subjects were middle school students, the recall bias should be smaller, as the time since the experience of CSA was shorter. Alternatively, the observed prevalence may suggest that the total prevalence of CSA is increasing in China. This study revealed that the male prevalence of CSA was higher than that of females $(P<0.001)$, which is consistent with the findings that boys were more likely to report CSA than girls [37]. The higher prevalence of CSA among male students in the study may be due to the broad definitions of sexual harassment, which include forced exposure to pornography and verbal sexual harassment. Male students may have more chances of being exposed to sexual harassment than female students, which may lead to a high prevalence of CSA among male students. In the context of general Chinese culture and the one-child policy, CSA has been considered too sensitive to discuss publicly [37]. School-aged girls are probably more likely to underreport their experiences. Parental supervision of children, especially girls, is generally strict due to the moral value placed on women's chastity in Chinese culture, which may protect Chinese girls from experiencing CSA [39]. When the issue of CSA in China has been discussed in the past, attention has mainly been focused on females as the key at-risk population. However, this study suggests that the CSA prevalence among male adolescent students can be quite alarming, and more prevention should be considered.
Similar to other studies [11, 40], we found numerous factors related to attitudes toward premarital sex. After controlling for sex, grade, one-child family status, left-behind status of middle school students, gender role score, a history of exposure to pornographic content on electronic media, a history of dating or falling in love with somebody, and parents' and friends' attitudes toward premarital sex, we found that among the general population, those who had CSA experience had more open attitudes toward premarital sex. The stratified analysis also showed that middle school students who had CSA experience were more open to premarital sex in the male and total student samples. According to social cognitive theory (SCT), under the combined effect of direct experience and result expectations, sexually curious middle school students who have experienced SCA will be more open to premarital sex than others. Among them, CSA can be considered a direct experience process in childhood, and the less serious health consequences are the positive outcome expectations. A previous study also suggested that those with a history of CSA had greater motives to use sex to cope with negative impacts and engaged in more risky sexual behaviors. This relationship was observed among male youth but not among female youth [40], which is similar to our finding. Based on the notion that masculinity norms (gender-based, heterocentric stereotypes) might drive increased sexual risk taking among males with a history of CSA compared to that in males without CSA experience, males with a history of CSA may utilize sex to manage distress and gain social approval [41]. Due to the male-dominated sexual culture in traditional Chinese culture, males' openness about sexual behaviors may greatly affect the premarital sexual behaviors of teenagers. However, in our study, a relationship between CSA experience and PSP was also found among female students. The results also indicated that female students expressed a desire for more gender equality in relationships, as more males than females in the sample held double standards about PSP. Therefore, women who suffer CSA will inevitably suffer gender inequality and deal with the negative impact of CSA experience, which can potentially manifest as greater openness to premarital sex. Therefore, the intervention of premarital sexual behaviors of middle school students should consider CSA experience, regardless of whether the intervention is with male or female groups.

Double standards (students being more permissive about premarital sex initiated by males than by females) were common among both male and female students but more pronounced among males, who are generally more open toward premarital sex than women because of cultural norms of masculinity. Meanwhile, male high school students who had experienced CSA were also more likely 
Table 3 Quantity (prevalence) of respondents with a history of CSA, grouped by sociodemographic characteristics

\begin{tabular}{|c|c|c|c|}
\hline Self-reported economic status characteristics & Total $(n=2292)$ & Male $(n=1091)$ & Female $(n=1201)$ \\
\hline \multicolumn{4}{|l|}{ Sex } \\
\hline Male & $199(18.2)^{* *}$ & - & - \\
\hline Female & $155(12.9)$ & - & - \\
\hline \multicolumn{4}{|l|}{ Grade } \\
\hline Middle school & $172(14.4)$ & $95(16.3)$ & $77(12.5)$ \\
\hline High school & $182(16.6)$ & $104(20.4)$ & $78(13.3)$ \\
\hline \multicolumn{4}{|l|}{ Left-behind student } \\
\hline Yes & $196(15.6)$ & $99(17.4)$ & $97(14.1)$ \\
\hline No & $140(14.9)$ & $87(18.2)$ & $53(11.5)$ \\
\hline \multicolumn{4}{|l|}{ Residence } \\
\hline Rural & $190(14.9)$ & $103(18.3)$ & $87(12.3)$ \\
\hline Urban & $160(16.0)$ & $94(18.2)$ & $66(13.8)$ \\
\hline \multicolumn{4}{|l|}{ Self-reported economic status } \\
\hline Low & $126(20.1)^{*}$ & $71(22.4)^{*}$ & $55(17.7)^{*}$ \\
\hline Middle & $210(13.5)^{\mathrm{a}}$ & $114(16.1)^{\mathrm{a}}$ & $96(11.4)^{\mathrm{a}}$ \\
\hline High & $12(17.7)$ & $10(22.2)$ & $2(8.7)$ \\
\hline \multicolumn{4}{|l|}{ One-child family } \\
\hline Yes & $34(11.9)$ & $22(13.8)$ & $12(9.5)$ \\
\hline No & $320(15.9)$ & $177(19.0)$ & $143(13.3)$ \\
\hline \multicolumn{4}{|l|}{ Divorced parents } \\
\hline Yes & $31(14.4)$ & $18(18.4)$ & $13(11.0)$ \\
\hline No & $323(15.6)$ & $181(18.2)$ & $142(13.1)$ \\
\hline \multicolumn{4}{|l|}{ Living or deceased parents } \\
\hline At least one parent deceased & $9(8.5)^{*}$ & $4(8.5)$ & $5(8.5)$ \\
\hline No & $345(15.8)$ & $195(18.7)$ & $150(13.1)$ \\
\hline \multicolumn{4}{|l|}{ Father's education level } \\
\hline Primary school or below & $111(15.5)$ & $54(18.0)$ & $57(13.7)$ \\
\hline Middle school & $162(15.3)$ & $93(18.8)$ & $69(12.3)$ \\
\hline High school and above & $51(17.0)$ & $37(19.7)$ & $14(12.5)$ \\
\hline \multicolumn{4}{|l|}{ Mother's education level } \\
\hline Primary school or below & $165(15.9)$ & $86(19.3)$ & 79 (13.3) \\
\hline Middle school & $116(15.6)$ & $70(18.7)$ & $46(12.5)$ \\
\hline High school and above & $34(15.0)$ & $20(17.0)$ & $14(12.8)$ \\
\hline \multicolumn{4}{|l|}{ History of dating or falling in love with somebody } \\
\hline Yes & $209(28.9)^{* *}$ & $117(30.5)^{* *}$ & $92(27.1)^{* *}$ \\
\hline No & $125(8.6)$ & $73(11.1)$ & $52(6.5)$ \\
\hline \multicolumn{4}{|l|}{ Friends' approval of premarital sex } \\
\hline Yes and other responses & $288(16.1)$ & $176(18.7)$ & $112(13.3)$ \\
\hline No & $66(13.0)$ & $23(15.3)$ & $43(12.0)$ \\
\hline \multicolumn{4}{|l|}{ Parents'approval of premarital sex } \\
\hline Yes and other responses & $254(15.2)$ & $169(18.6)$ & $85(11.1) *$ \\
\hline No & $100(16.1)$ & $30(16.4)$ & $70(16.0)$ \\
\hline \multicolumn{4}{|c|}{ History of exposure to pornographic content on electronic media } \\
\hline Yes & $114(31.1)^{* *}$ & $91(29.7)^{* *}$ & $23(37.7)^{* *}$ \\
\hline No & $240(12.5)$ & $108(13.8)$ & $132(11.6)$ \\
\hline
\end{tabular}

The test level is $a=0.05$; "a" indicates that the difference compared with the first group is statistically significant, and " $\mathrm{b}$ " indicates that the difference compared with the second group is statistically significant

${ }^{*} P<0.05$

${ }^{* *} P<0.001$ 
Table 4 Coefficients (95\% confidence intervals for $\beta$ ) from the stepwise linear regression model assessing the influencing factors of premarital sexual permissiveness, grouped by sex

\begin{tabular}{|c|c|c|c|}
\hline Variables & Total $(n=2292)$ & Male $(n=1091)$ & Female $(n=1201)$ \\
\hline Sex (ref: male) & $6.18(4.56 \sim 7.80)^{* *}$ & - & - \\
\hline Grade (ref: middle school) & $-2.49(-3.99 \sim-0.98)^{*}$ & $-5.57(-8.28 \sim-2.87)^{* *}$ & - \\
\hline One-child family (ref: no) & $-3.95(-6.02 \sim-1.88)^{* *}$ & $-4.55(-7.93 \sim-1.18)^{*}$ & $-3.56(-6.06 \sim-1.05)^{*}$ \\
\hline Left-behind student (ref: no) & $1.47(0.05 \sim 2.89)^{*}$ & - & $2.87(1.27 \sim 4.47)^{* *}$ \\
\hline Gender role attitudes & $0.17(0.10 \sim 0.24)^{* *}$ & $0.19(0.07 \sim 0.31)^{*}$ & $0.10(0.02 \sim 0.18)^{*}$ \\
\hline $\begin{array}{l}\text { History of exposure to pornographic content on electronic } \\
\text { media (ref: no) }\end{array}$ & $-6.88(-8.90 \sim-4.86)^{* *}$ & $-6.94(-9.90 \sim-3.99)^{* *}$ & - \\
\hline History of dating or falling in love with somebody (ref: no) & $-4.66(-6.24 \sim-3.07)^{* *}$ & $-5.40(-8.18 \sim-2.61)^{* *}$ & $-3.87(-5.59 \sim-2.15)^{* *}$ \\
\hline Friends' approval of premarital sex (ref: no) & $-4.51(-6.28 \sim-2.74)^{* *}$ & $-5.30(-8.97 \sim-1.63)^{*}$ & $-3.43(-5.20 \sim-1.65)^{* *}$ \\
\hline Parents' approval of premarital sex (ref: no) & $-3.06(-4.70 \sim-1.42)^{* *}$ & $-4.77(-8.12 \sim-1.42)^{*}$ & $-1.81(-3.48 \sim-0.14)^{*}$ \\
\hline CSA (ref: no) & $-2.84(-4.81 \sim-0.88)^{*}$ & $-3.76(-7.00 \sim-0.52)^{*}$ & $-2.79(-5.18 \sim-0.40)^{*}$ \\
\hline Constant & $72.98(67.46 \sim 78.51)$ & $83.53(74.52 \sim 92.55)$ & 85.61 (79.08 92.13) \\
\hline
\end{tabular}

${ }^{*} P<0.05$

${ }^{* *} P<0.001$

Table 5 Odds ratio (95\% confidence interval) from the logistic regression model assessing the influencing factors of holding a double standard about premarital sexual permissiveness

\begin{tabular}{llll}
\hline Variables & MODEL 1 & MODEL 2 & MODEL 3 \\
\hline Sex (ref: male) & - & - & $0.65(0.52 \sim 0.82)^{*}$ \\
History of dating or falling love with somebody (ref: no) & - & $1.79(1.29 \sim 2.49)^{*}$ & $1.38(1.09 \sim 1.75)^{*}$ \\
Gender role attitudes & $0.98(0.96 \sim 0.99)^{*}$ & $0.98(0.97 \sim 1)^{*}$ & $0.98(0.97 \sim 0.99)^{*}$ \\
CSA (ref: no) & $1.63(1.11 \sim 2.39)^{*}$ & - & $1.41(1.05 \sim 1.88)^{*}$ \\
History of exposure to pornographic content on electronic media & $1.59(1.13 \sim 2.23)^{*}$ & - & $1.36(1.01 \sim 1.83)^{*}$ \\
(ref: no) & & & 3.97 \\
Constant & 3.73 & 1.97 & 3.94 \\
\hline
\end{tabular}

Note: MODEL 1: male middle school students with a double standard

MODEL 2: female middle school students with a double standard

MODEL 3: middle school students with a double standard

All three models were conducted by controlling the covariates: grade, divorced parents, living or deceased parents, self-reported economic status, one-child family, father's and mother's education level, residence, and left-behind status of middle school students. The covariate sex was controlled only for model 3 . ${ }^{*} P<0.05$

to hold double standards than other students. This finding could be explained by the fact that CSA experience was reported to be higher in male high school students who were potentially more open about premarital sex. The CSA experience rate was also reported to be higher in males than in females.

This study had some limitations. First, although the study involved a large-scale middle school student sample in Luzhou city, Sichuan Province, which is a typical city that is representative of third-tier cities in China, the sample was drawn from only one city. Thus, the sample was representative only of middle school students with similar socioeconomic statuses. The generalizability of the findings to populations in other cities, especially those with other socioeconomic contexts, is limited. Second, although we used self-administered anonymous questionnaires, underreporting bias might still exist because the topic of premarital sex is sensitive and unacceptable to talk about for most Chinese middle school students in Chinese cultural settings. However, we explained the purpose and significance of the survey to the respondents before the survey, and respondents completed the survey independently and anonymously, with students seated the same distance from students that they are during exams to safeguard the respondents' privacy and minimize bias. Third, in our study, we found that middle school students with CSA experience held more open attitudes toward premarital sex than those without CSA experience. However, as with many other self-reporting surveys, there may have been a gap between the reports and reality. Hence, our findings on the effect of CSA experience on sexual attitudes may be tentative and need to be replicated with 
more empirical studies. Fourth, the definition of CSA in this study, which considers culture and population adaptation, was defined based on relevant research at home and abroad. However, this definition is inconsistent with the measurement of CSA used by other researchers and results in a decrease in comparability of research results. Fifth, in this study, we adopted a self-reporting method to collect information about the economic status of the respondents. This subjective reporting method may misclassify respondents into the wrong category. Furthermore, because the sample was cross-sectional, our findings on the effect of CSA on premarital sexual attitudes showed a possible association but not a causal relationship. We suggest that in future studies, longitudinal approaches should be utilized to better understand the causality between CSA experience and PSP.

Gender differences in CSA and the relationship between CSA and PSP were significant among middle school students in Luzhou. Child sex abuse may highly influence victims' attitudes toward premarital sex in their adolescent life, especially for male victims. Therefore, awareness to help prevent child sex abuse must be raised for families, schools and communities. In addition, child sex abuse preventive programs are crucial to reduce the risk of child sex abuse, promote sexual equality and develop positive attitudes toward premarital sex. Preventive programs can be conducted by both family and school interventions in various forms and settings, such as sex education in communities, kindergartens, and primary schools. To enhance the performance of sex education, relevant stakeholders should become involved, and more resources should be invested in to strengthen teacher training programs and facilitate active cooperation between families and schools. It is crucial to employ various measures to reduce the risk of child sex abuse, promote positive attitudes toward premarital sex and alleviate the impact of child sex abuse on sexual cognition and attitudes.

\section{Conclusions}

The findings showed that gender differences in CSA and the relationship between CSA and PSP were significant among middle school students in Luzhou, China. CSA experience is a significant factor in shaping adolescent sexual attitudes, especially among males. Some new directions for future research are indicated in the present study. The CSA experience of males should be given the same or even greater attention than that of females. Further research on adolescent sexual and reproductive outcomes should include the elements of CSA experience and examine differences and similarities between genders. In addition, future longitudinal studies on the premarital sexual behavior of adolescents need to further verify the relationship between CSA experience and attitudes toward premarital sex, as the specific pathway of this influence is not yet clear.

\begin{abstract}
Abbreviations
CSA: Childhood sexual abuse; STIs: Sexually transmitted infections; PSP: Premarital sexual permissiveness; SCT: Social cognitive theory; KAP: Knowledge, attitude, belief, practice theory.
\end{abstract}

\section{Supplementary Information}

The online version contains supplementary material available at https://doi. org/10.1186/s12889-021-12490-1.

Additional file 1: Figure 1. Residual graph of total, male and female students.

\section{Acknowledgments}

The authors would like to thank the researchers at the School of Public Health of Southwest Medical University, Luzhou, Center for Disease Control and Prevention Sichuan Province, Luzhou, and Education Bureau for their work and commitment to the project. The authors also thank all the respondents of this study.

\section{Authors' contributions}

$Y Y L, L Y$, and $F S$ designed the survey. YYL, LY, FS, WH, and TXZ contributed to the investigation and data collection. ZR, ZW and LMX performed the statistical analysis and wrote the manuscript. All authors read and approved the final manuscript.

\section{Funding}

This study was supported in part by grants from the Sichuan Research Center for Sexual Sociology and Sexual Education (SXJYB1619), China.

\section{Availability of data and materials}

The datasets used during the current study are available from the corresponding author upon reasonable request.

\section{Declarations}

Ethics approval and consent to participate

This study received approval from the Ethics Committee of The Affiliated Hospital of Southwest Medical University (No. KY2020151). Written informed consent was obtained from the participants' guardians.

Consent for publication

Not applicable.

Competing interests

The authors declare that they have no competing interests.

\section{Author details}

${ }^{1}$ School of Public Health, Southwest Medical University, Luzhou, China. ${ }^{2}$ Shanghai Pudong New Area Center for Disease Control \& Prevention, Shanghai, China.

Received: 11 August 2020 Accepted: 30 December 2021

Published online: 11 January 2022

\section{References}

1. Zhang P, Gao ES, Sun Q, Lou JQ, Zhang YM, Sun XM. Effect on familyrelated factors influencing premarital sex of adolescents. Chin J Health Stat. 2017:34(5):710-2. 
2. Sun X, Zhu GR, Ji CY, Wang ZZ. Analysis on sex behavior and its impact factors among outside school adolescents in outflow area. Chin J Sch Health. 2012;33(08):925-7.

3. Cao Y, Xiao H, Yan H, Li J, Li S. Prevalence and sex-related risk factors of premarital pregnancy and reproductive tract infections among female undergraduates in Wuhan, China. Asia Pac J Public Health. 2015;27(2_suppl):30S-40S.

4. Feng Y, Lou CH, Cheng Y, Gao ES, Niu HF, Tu XW. Study on the unintended pregnancy among the unmarried young adults in Shanghai. Chin Journal of School Health. 2010;11:1312-4.

5. Honarvar B, Salehi F, Barfi R, Asadi Z, Honarvar H, Odoomi N, et al. Attitudes toward and experience of singles with premarital sex: a populationbased study in Shiraz, Southern Iran. Arch Sex Behav. 2016;45(2):395-402.

6. Zuo X, Lou C, Gao E, Cheng Y, Niu H, Zabin LS. Gender differences in adolescent premarital sexual permissiveness in three Asian cities: effects of gender-role attitudes. J Adolesc Health. 2012;50(3):S18-25.

7. Zou Y, Yan H, Wu H, Chen R, Huang D, Li S. Female undergraduate fine arts students: a high-risk population for multiple sexual partners, unwanted pregnancy and sexually transmitted infections in China. Eur J Contracept Reprod Health Care. 2013;18(2):127-36.

8. Wang H, Long L, Cai H, Wu Y, Xu J, Shu C, et al. Contraception and unintended pregnancy among unmarried Female University students: a cross-sectional study from China. PLoS One. 2015;10(6):e130212.

9. Wu ZY. The situation and strategy of AIDS prevention and control in schools in China. Chin J Sch Health. 2015;11:1604-5.

10. Tang CS. Childhood experience of sexual abuse among Hong Kong Chinese college students. Child Abuse Negl. 2002;26(1):23-37.

11. Sun YP, Dong ZJ, Yi MJ, Sun DF. Childhood sexual abuses among 1307 adult students and analysis on results of symptom Checldist-90 test. Chinese J Pediatr. 2006;01:21-5.

12. Fang $X$, Fry DA, Ji K, Finkelhor D, Chen J, Lannen P, et al. The burden of child maltreatment in China: a systematic review. B World Health Organ. 2015:93(3):176-85.

13. Chen J, Dunne MP, Han P. Child sexual abuse in Henan province, China: associations with sadness, suicidality, and risk behaviors among adolescent girls. J Adolesc Health. 2006;38(5):544-9.

14. Lin D, Li X, Fan X, Fang X. Child sexual abuse and its relationship with health risk behaviors among rural children and adolescents in Hunan, China. Child Abuse Negl. 2011;35(9):680-7.

15. Danhua $L$, Xiaoming L, Fang $X$, Lin X. Childhood sexual abuse and sexual risks among young rural-to-urban migrant women in Beijing, China. AIDS Care. 2011;23(supp 1):113-9.

16. Chen AC, Neilands TB, Chan S, Lightfoot M. Contextual influence of Taiwanese adolescents' sexual attitudes and behavioral intent. Nurs Health Sci. 2016;18(3):355-61.

17. Sneed CD, Tan HP, Meyer JC. The influence of parental communication and perception of peers on adolescent sexual behavior. J Health Commun. 2015;20(8):888-92.

18. Doornwaard SM, Bickham DS, Rich M, ter Bogt TFM, van den Eijnden RJJM. Adolescents' use of sexually explicit internet material and thei sexual attitudes and behavior: parallel development and directional effects. Dev Psychol. 2015;51(10):1476-88.

19. Chiao C, Yi CC, Ksobiech K. Exploring the relationship between premarital sex and cigarette/alcohol use among college students in Taiwan: a cohort study. BMC Public Health. 2012;12:527.

20. Su PY, Tao FB, Cao XJ, Hao JH, Zhang CH, Chen T. Study on the relationship between sexual abuse in childhood and psychiatric disorder, risky behaviors in youthhood among 1386 medicos. Chinese J Epidemiol. 2008;1:94-5.

21. Garcia-Vega E, Rico R, Fernandez P. Sex, gender roles and sexual attitudes in university students. Psicothema. 2017;29(2):178-83.

22. Dave VR, Makwana NR, Yadav BS, Yadav S. A study on high-risk premarital sexual behavior of college going male students in Jamnagar City of Gujarat, India. Int J High Risk Behav Addict. 2013;2(3):112-6.

23. Yan H, Chen W, Wu H, Bi Y, Zhang M, Li S, et al. Multiple sex partner behavior in female undergraduate students in China: a multi-campus survey. BMC Public Health. 2009;9(1):305.

24. Yip PS, Zhang H, Lam TH, Lam KF, Lee AM, Chan J, et al. Sex knowledge, attitudes, and high-risk sexual behaviors among unmarried youth in Hong Kong. BMC Public Health. 2013;13:691.
25. Li S, Chen R, Cao Y, Li J, Zuo D, Yan H. Sexual knowledge, attitudes and practices of female undergraduate students in Wuhan, China: the onlychild versus students with siblings. PLoS One. 2013;8(9):e73797.

26. Bandura A. Social foundations of thought and action: a social cognitive theory. Englewood Cliffs: Prentice-Hall; 1986

27. Zhou J, Fan T. Understanding the factors influencing patient E-health literacy in online health communities (OHCs): a social cognitive theory perspective. Int J Environ Res Public Health. 2019;16(14):2455.

28. Baranowski T, Perry CL, Parcel GS. How individuals, environments, and health behavior interact. In: Glanz K, Rimer BK, Lewis FM, editors. Health behavior and health education: theory, research, and practice. 3rd ed. San Francisco: Jossey-Bass; 2002. p. 165-84.

29. Zhang W, Fan S, Xie ML, Li PL, Ye YL. Analysis of the occurrence and influencing factors of childhood sexual abuse of middle school students in Luzhou City. Chinese J Sch Health. 2018;06:854-6.

30. II R. The social context of premarital sexual permissiveness. New York: Holt, Rinehart, and Winston; 1967.

31. Kreager DA, Staff J, Gauthier R, Lefkowitz ES, Feinberg ME. The double standard at sexual debut: gender, sexual behavior and adolescent peer acceptance. Sex Roles. 2016;75(7-8):377-92.

32. Petersen JL, Hyde JS. A meta-analytic review of research on gender differences in sexuality, 1993-2007. Psychol Bull. 2010;136(1):21-38.

33. Cheng Y, Lou C, Gao E, Emerson MR, Zabin LS. The relationship between external contact and unmarried Adolescents' and young Adults' traditional beliefs in three east Asian cities: a cross-sectional analysis. J Adolesc Health. 2012;50(3):S4-S11.

34. Li YY, Xu SF, Zhou Y, Chen JG, Zhao R, Ji HL, et al. Status of parents' sex education to their children among students in senior grades of primary schools and middle schools. Chinese J Health Educ. 2017;33(09):830-3.

35. Wang JJ. Analysis of the situation of children's sex education in China from the incident of child sexual assault. J Educ Institute Jilin Province. 2014;30(11):14-5

36. Ma Y. Prevalence of childhood sexual abuse in China: a Meta-analysis. J Child Sex Abus. 2018;27(2):107-21.

37. Chan KL, Yan E, Brownridge DA, Ip P. Associating child sexual abuse with child victimization in China. J Pediatr. 2013;162(5):1028-34.

38. Xu Y, Zheng Y. Prevalence of childhood sexual abuse among lesbian, gay, and bisexual people: a Meta-analysis. J Child Sex Abus. 2015;24(3):315-31.

39. Li CG, Wei L. Concept of "chastity" in Chinese traditional ethics. J Jiangxi Normal Univ (Philosophy and Social Sciences Edition). 2010;43(05):184-94

40. Wekerle C, Goldstein AL, Tanaka M, Tonmyr L. Childhood sexual abuse, sexual motives, and adolescent sexual risk-taking among males and females receiving child welfare services. Child Abuse Negl. 2017;66:101-11.

41. Homma Y, Wang N, Saewyc E, Kishor N. The relationship between sexual abuse and risky sexual behavior among adolescent boys: a Meta-analysis. J Adolesc Health. 2012;51(1):18-24.

\section{Publisher's Note}

Springer Nature remains neutral with regard to jurisdictional claims in published maps and institutional affiliations. 